\title{
Tecendo fios dos sonhos na Psicanálise e em territórios compartilhados: aurora da psiquê? ${ }^{146}$
}

\author{
Paulo Duarte Guimarães Filho ${ }^{147}$
}

\author{
Tecendo a manhã
}

Um galo sozinho não tece uma manhã:
ele precisará sempre de outros galos.
De um que apanhe esse grito que ele
e o lance a outro; de um outro galo
que apanhe o grito de um galo antes
e o lance a outro; e de outros galos
que com muitos outros galos se cruzem
os fios de sol de seus gritos de galo,
para que a manhã, desde uma teia tênue, se vá
tecendo, entre todos os
E se encorpando em tela, entre todos,
se erguendo tenda, onde entrem todos,
se entretendendo para todos, no toldo
(a manhã) que plana livre de armação.
A manhã, toldo de um tecido tão aéreo
que, tecido, se eleva por si: luz balão.

João Cabral de Melo Neto

Nosso tema é interdisciplinar e o poema de João Cabral é valioso para exprimir experiências que tenho tido, ao tecer fios da psicanálise com os de outras disciplinas (Psicanálise nas Fronteiras: indo além e retornando a clínica). Uma das mais reveladoras é em relação aos sonhos/pesadelos, nos aproximando de algo colocado com tanta riqueza poética por Cabral na imagem da: "luz balão". Outra figura no poema expõe bem o valor da associação do que vem de diferentes territórios, ao apontar que um galo sozinho não tece a manhã, precisando do canto de outros galos. Assim, o mais relevante para o que vamos tratar, é como as imagens deste poema têm paralelos com o modo pelo qual a tecelagem dos fios dos sonhos/pesadelos, na psicanálise e em territórios compartilhados do seu estudo, levam a sugestões instigantes sobre o papel dos fenômenos oníricos nas origens e na continuação do funcionamento da psiquê, vida mental/emocional humana. Dispondo desses elementos, essa tecelagem

\footnotetext{
146 Trabalho apresentado na mesa "Sonhos: território compartilhado" no II Simpósio Bienal SBPSP "Fronteiras da Psicanálise: a clínica em movimento" no dia 29 de agosto de 2020.

${ }^{147}$ Membro efetivo e analista didata de adultos e crianças da SBPSP, Mestre em Filosofia pela PUC-SP, coordenador do grupo de Psicanálise e Semiótica (SBPSP).
} 
favorece o entendimento de como os sonhos estiveram nas bases da criação da psicanálise, com Freud, e depois com Bion, numa de suas ampliações mais notáveis.

De fato, para chegar ao que pode ser alcançado através da tecelagem de verificações sobre os sonhos na psicanálise, com as realizadas em territórios compartilhados, é necessário partir das decifrações fundamentais de Freud a respeito dos fenômenos oníricos. Tendo esta base, pode ser seguido como ela forneceu elementos para o reconhecimento, por parte de Bion, de que os processos presentes nos sonhos ocorriam também na vigília, tendo um papel central no processamento e na capacidade de lidar com as mobilizações da vida emocional. Bion chegou a isso, verificando a ausência de sonhos nos psicóticos e, a partir daí, de que eles tinham o importante papel referido antes, o que levou a sua concepção da função alfa. Continuando, é necessário lembrar que, em termos de Bion, o processamento das experiências emocionais, ou operação da função alfa, se refere ao lidar com as manifestações emocionais, primitivamente por meio da capacidade de continência/reverie da mãe, seguida de meios expressivos presentes nos sonhos e já identificados por Freud, como os da representação por imagens, a condensação e o deslocamento. O que Bion salienta, é como estas figurações têm um papel fundamental na continência, na representação e no lidar com as mobilizações emocionais. Distinguindo esta importância do sonhar e da função alfa, Bion também pode reconhecer, com maior clareza, a presença de funcionamentos mentais em que isto não ocorre, sendo as representações vividas concretamente como fatos. Identificou, então, o que chamou de elementos beta, próprios dos processos psicóticos, possibilitando um melhor reconhecimento do funcionamento da chamada "parte psicótica da personalidade", ao lado da não psicótica.

Estas concepções essenciais de Bion foram formuladas em nível de grande abstração. Para facilitar o acompanhamento da proximidade entre elas e verificações sobre os sonhos noutros territórios, bem como as possibilidades de tecelagem desses elementos, vale a pena aproveitar o modo como Ogden usou concepções de Bion para o que abordou no trabalho: "Esta Arte a Psicanálise. Sonhando sonhos não sonhados e choros interrompidos”. De grande interesse, no caso, são as colocações no sentido de que a arte da psicanálise tem a ver com o levar a que os pesadelos possam ser sonhados, e nesta direção Ogden faz 
ligações dos pesadelos com os elementos beta e dos sonhos com a operação da função alfa. Estes termos de Ogden/Bion dão indicações de um lugar central dos pesadelos/sonhos na vida emocional humana e são de grande valor para o reconhecimento de seus elos, e da tecelagem que pode advir daí, com o que verificaremos de outros territórios.

Devemos começar dizendo que ouvimos um canto de galo na psicanálise e que, para facilitar a escuta no território vizinho, vai ser necessário o uso do que foi distinguido deste fio do canto, "pesadelo", na psicanálise, para ajudar na escuta do canto do outro território, conforme aparece no trabalho: "The reinterpretation of dreams: an evolutionary hypothesis of the function of dreaming", de Antti Revonsuo, na publicação: "Sleep and Dreaming - Scientific Advances and Reconsiderations" (2003). O autor parte de um levantamento que evidencia a predominância de situações de perigo como fatores mobilizadores dos sonhos. Destaca este dado e o correlaciona com o fato de que os pesadelos/sonhos ocorrem também em determinadas espécies animais. A partir dos pesadelos/sonhos nos animais, vem a parte mais interessante da hipótese de Revonsuo, no sentido de que um processo com a natureza e complexidade dos sonhos não acontece e se mantem no plano biológico, caso não tenha um papel importante para a sobrevivência. Esses elementos foram levando à noção de que os processos oníricos tenham tido como uma de suas funções, nas suas origens nos animais, a da reprodução de situações de perigo durante o sono. Desse modo, favoreceriam seus registros e contribuiriam para o enfrentamento de tais situações e para a sobrevivência. Apesar dos aspectos conjecturais dessa hipótese, o que acrescentamos de nossa parte, é que ela tem uma base e está de acordo com ocorrências conhecidas até hoje em seres humanos, na chamada "Síndrome do Stress Pós-Traumático", nas quais se destaca a repetição de pesadelos/sonhos ligados aos traumas. Isto também foi reconhecido por Freud, em "Além do Princípio do Prazer", nas chamadas "neuroses traumáticas". Essas ocorrências dão consistência à conjectura de Revonsuo, a qual também é reforçada e ganha uma dimensão muito mais ampla, se considerarmos seus nexos com o referido sobre as ideias de Bion/Ogden a respeito dos sonhos/pesadelos. Há outra tecelagem importante das concepções de Bion com as de Revonsuo, no sentido de que, a partir de uma função inicial nos animais, voltada para o perigo e o traumático associado a ele, os processos oníricos tenham evoluído para 
representarem de modo mais amplo, também outras mobilizações emocionais intensas, aí incluindo aquelas presentes nos desejos sexuais e em conflitos envolvidos com eles, conforme foi estudado amplamente por Freud.

Se os fios dos sonhos/pesadelos distinguidos por Freud e Bion na psicanálise, e Revonsuo no plano neurobiológico, já lançam alguma luz sobre o papel de tais fenômenos no início e em aspectos fundamentais do funcionamento mental humano, psiquê, esse clareamento se amplia bastante através do fio, também ligado a pesadelos/sonhos, e que foi trazido à luz no livro "A Filosofia do Sonho", de Christoph Türcke, filósofo alemão da conhecida Escola de Frankfurt. Apesar deste fio ter sido verificado de um modo inteiramente independente noutro território, há uma articulação forte, e de certo modo uma continuidade bem significativa, entre ele e os fios considerados antes. Um dado bastante interessante a respeito dessa continuidade é que ela não aparece diretamente, diante de um primeiro olhar para as concepções de Türcke. Isto ocorre na medida em que o foco principal das considerações deste autor foram os rituais de sacrifício e a universalidade de sua presença nos primórdios da condição humana, conforme as amplas verificações da paleontologia. O filósofo alemão destacou o papel de vivências traumáticas e de pavor na base desses rituais, bem como da repetitividade que faz parte deles. O título do seu livro, "A Filosofia do Sonho", tem a ver com o fato de que usou noções centrais de Freud sobre os sonhos, para o entendimento dessas manifestações, no caso as de condensação, deslocamento, representação por imagens e reversão. Elas contribuíram para Türcke pensar como as repetições de expressões de manifestações emocionais ligadas ao traumático nos rituais de sacrifício, teriam tido um papel básico na própria origem da mente humanas. O salientado por aquele autor foi como processos de condensação e deslocamento, esclarecidos por Freud nos processos oníricos, também fariam parte de expressões verbais repetidas com grande intensidade nos rituais de sacrifício, o que teria feito parte da própria origem da linguagem e da mente humana. Embora esses elementos tenham levado o filósofo alemão a esclarecimentos consistentes, é bem interessante verificar que, ao lado do uso de noções freudianas, faltou a Türcke a consideração dos acréscimos apontados antes de Bion sobre o tema, o que dá indicação de dificuldades e lacunas que podem ocorrer num trabalho interdisciplinar. Se tivesse levado em conta as contribuições de Bion, seria 
possível para Türcke pensar em como a repetitividade de elementos traumáticos nos rituais de sacrifício estaria relacionada com a repetitividade de pesadelos/sonhos nas experiências traumáticas em geral, conforme indicado anteriormente, o que certamente daria uma dimensão bem mais ampla a sua "filosofia do sonho".

Considerando esses dados, eles facilitam a percepção do entrelaçamento entre o verificado nos dois outros territórios e o que temos na psicanálise. De fato, um olhar psicanalítico permite distinguir as ligações, como não foi feito pelos próprios autores, entre as sugestões de Revonsuo e as de Türcke. Nessa direção, aparecem com destaque os nexos entre a ideia de Revonsuo, dos sonhos nos animais diante de situações ameaçadoras, com as colocações de Türcke a respeito do papel das experiências traumáticas nos rituais de sacrifício. Desse modo, as propostas de Türcke dariam uma maior amplitude à hipótese de Revonsuo, ao ser levado em conta como os pesadelos/sonhos que aparecem nos animais, transbordam para a vigília, ao estarem associados aos rituais de sacrifício e, depois, conforme foi sendo verificado na psicanálise, evoluindo para ter um papel central na continência, na expressão e no lidar com a vida emocional, tanto no sono como na vigília.

Apesar da relevância das contribuições desses dois autores, não é uma casualidade que eles não tenham feito os entrelaçamentos e expansões conceituais que estão sendo propostos. Examinamos como essas ligações só foram possíveis a partir do uso de informações e noções desenvolvidas na psicanálise sobre os sonhos/pesadelos. Sendo tecidos esses fios, é possível considerar como o estudo dos dois autores mencionados fornece elementos para uma ampliação do reconhecimento das raízes que levaram os sonhos a terem um papel tão central e importante na vida emocional humana. Sobre esse ponto, é de extraordinária importância para a validade da psicanálise como conhecimento, que os fios encontrados nos territórios do estudo compartilhado dos sonhos possam ser entrelaçados, com tal grau de compatibilidade, com os fios encontrados no território psicanalítico. Ao mesmo tempo, a tecelagem e percepção desses fios que vêm dos primórdios, aurora, da constituição e depois seguem na continuação da psiquê humana, abrem um enorme campo para expansões das concepções psicanalíticas sobre tais fenômenos. Territórios 
compartilhados e abertos para investigação por espíritos aventureiros na psicanálise?

Em virtude do tempo, não serão consideradas possibilidades de articulações do que acabou de ser apresentado com outros fios existentes na neurociência. No caso, sobre os sonhos nos processos de memorização e de tecelagens entre eles e os fios sobre o tema desenvolvidos por Freud e Bion. Escrevi a respeito em: "Mente, corpo, sonhos: um percurso intrincado", (Revista Brasileira de Psicanálise,1995); e ("Agir, alucinar, sonhar: como fica a árvore sem as raízes?”, (Simpósio Internacional: "Bion em São Paulo: Ressonâncias”, (1996, publicado no livro com o mesmo nome). 